\title{
THE ANTIMICROBIAL EFFICACY OF ETHANOLIC EXTRACT OBTAINED FROM FICUS BENGHALENSIS L. (MORACEAE) LEAVES
}

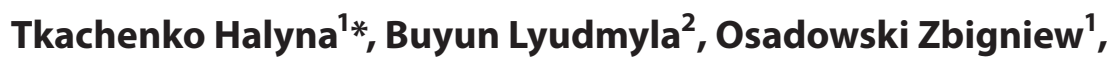 \\ Honcharenko Vitaliy ${ }^{4}$, Prokopiv Andriy ${ }^{3,4}$
}

\author{
${ }^{1}$ Institute of Biology and Environmental Protection, Pomeranian University in Slupsk, Poland \\ ${ }^{2}$ M.M. Gryshko National Botanical Garden, National Academy of Sciences of Ukraine, Kyiv, Ukraine \\ ${ }^{3}$ Botanical Garden of Ivan Franko Lviv National University, Lviv, Ukraine \\ ${ }^{4}$ Ivan Franko Lviv National University, Lviv, Ukraine
}

Received 25.6.2017 Revised 29.6.2017 Published 30.11.2017

Medicinal plants have a great potential for providing novel drug leads with proven mechanism of action. The aim of our study was to investigate in vitro antimicrobial activity of ethanolic extract prepared from Ficus benghalensis L. leaves against Gram-positive (Staphylococcus aureus, methicillin-resistant Staphylococcus aureus locally isolated and Streptococcus pneumoniae) and Gram-negative bacterial strains (Klebsiella pneumoniae, Pseudomonas aeruginosa and Escherichia coli), as well as against fungus Candida albicans to determine the possible use of this plant in preventing infections. Antimicrobial activity of crude extract of the plant sample was evaluated by the paper disc diffusion method. Ethanolic extract obtained from leaves of Ficus benghalensis showed moderate antibacterial activity against Staphylococcus aureus, Escherichia coli, and Pseudomonas aeruginosa, while no significant antibacterial activity against Klebsiella pneumoniae and Streptococcus pneumoniae, methicillin-resistant S. aureus and Candida albicans was demonstrated. Among the tested microbial strains, bacteria were found to be more sensitive to many of the test agents than fungi. The antibacterial activity was more pronounced on the Gram-positive bacteria (Staphylococcus aureus) than the Gram-negative bacteria (Escherichia coli and Pseudomonas aeruginosa). The broad antibacterial activities of this extract could be as a result of the plant secondary metabolites (carbohydrates, reducing sugars, sterols, glycosides, phenolic compounds, tannins, saponins and flavonoids). Therefore, Ficus benghalensis has a great medicinal potential for the therapy of infections induced by Gram-positive and Gram-negative bacteria and may be used as a natural antiseptic and antimicrobial agent in medicine. Further investigation is necessary to identify those bioactive compounds, which will be a platform for clinical applications.

Keywords: Ficus benghalensis L.; ethanolic extract; leaves; Gram-positive and Gram-negative bacterial strains; antimicrobial activity; disc diffusion technique

\section{Introduction}

Ficus benghalensis $\mathrm{L}$. is a monoecious evergreen tree reaching 20 (or more) $\mathrm{m}$ in height, usually hemiepiphytic, rarely terrestrial, with puberulous leafy twigs. The species is native to India and Pakistan. It is a classic example of the banyan-type tree having aerial adventitious roots that grow down from the branches into the soil forming additional woody trunks, hence enabling an ageing tree to spread out laterally and cover a wide area. Leaves are coriaceous, 7-30 cm long and 4-20 cm wide, ovate to

*Corresponding author: Halyna Tkachenko, Institute of Biology and Environmental Protection, Pomeranian University in Slupsk, Poland, $\bowtie$ tkachenko@apsl.edu.pl 
elliptic with rounded or cordate base, puberulous on the veins. Its small sessile puberulous figs, up to $2 \mathrm{~cm}$ in diameter, contain all the three flower types, i.e., the seed, gall, and staminate flowers, and turn red at maturity (Berg and Corner, 2014).

The plant is well known due to its medicinal potential in ayurvedic medicine and commonly known as "banyan tree" in ayurvedic literature. It is astringent to bowels; useful in treatment of biliousness, ulcers, erysipelas, vomiting, vaginal complains, fever, inflammations, leprosy. According to Unani system of medicine, its latex is aphrodisiac, tonic, vulnerary, and useful in piles, nose-diseases, gonorrhea, inflammations etc. treatment (Ahmad et al., 2011). The aerial root is styptic, useful in treatment of syphilis, biliousness, dysentery, inflammation of liver, etc (Varanasi, 2007).

Various scientific studies have been carried out on Ficus benghalensis and various pharmacological activities have been reported. It has been reported to possess immune-modulatory, hypoglycemic, antioxidant, anti-stress and anti-allergic, and anthelmintic activities (Garg and Paliwal, 2011). In Ayurveda, Ficus benghalensis is used for the treatment of skin disorder, rheumatism, diabetes, of diarrhea, dysentery and piles, teeth disorders, nerve disorder, and menorrhagia, to boost immune system, as antiseptic, aphrodisiac, hemostatic agent. This plant is used throughout India for the purpose of complication related to blood, bone, endocrine system, toothache, gastric disorder, reproductive, and urinary disorders, and fever. The extracts of Ficus benghalensis were also reported to inhibit insulinase activity from liver and kidney, fruit extracts exhibited anti-tumor activity, and flavonoid compounds obtained from the bark of Ficus benghalensis possess antioxidant activity in hyperlipidemic rats. Various extracts of Ficus benghalensis were screened for its anti-allergic and antistress potential in asthma by milk induced leukocytosis and milk induced eosinophilia (Panday and Rauniar, 2016). Traditionally, it is used for wounds, fever, swollen joints, inflammations, and ulcers (Patel et al., 2010).

The phytochemical screening of Ficus benghalensis revealed the presence of saponins, tannins and flavonoids in aqueous and methanolic extract (Aswar et al., 2008). Levels of total phenolic, total flavonol and total flavonoid compounds in aerial roots in $70 \mathrm{mg} / \mathrm{g}$ of extract, $3 \mathrm{mg} / \mathrm{g}$ quercetin equivalent and $5 \mathrm{mg}$ quercetin equivalent/g extract have also been reported (Sharma et al., 2009). Some natural compounds have been isolated from the bark (Subramanian and Misra, 1978).

It is important to investigate scientifically this plant which has been used in traditional medicines as potential sources of novel antimicrobial compounds. So, the present study was conducted to investigate in vitro antimicrobial activity of ethanolic extracts prepared from Ficus benghalensis leaves against Gram-positive and Gram-negative bacteria to determine the possible use of this plant in preventing infections.

\section{Materials and methodology}

The leaves of Ficus benghalensis were collected in M.M. Gryshko National Botanical Garden (Kyiv, Ukraine) and Botanical Garden of Ivan Franko Lviv National University (Lviv, Ukraine) (Figure 1). The whole collection of tropical and subtropical plants at both Gardens (including Ficus spp. plants) has the status of a National Heritage Collection of Ukraine. The sampled leaves were brought into the laboratory for antimicrobial studies. Freshly crushed leaves were washed, weighted, and homogenized in $96 \%$ ethanol (in ratio $1: 10$ ) at room temperature. 


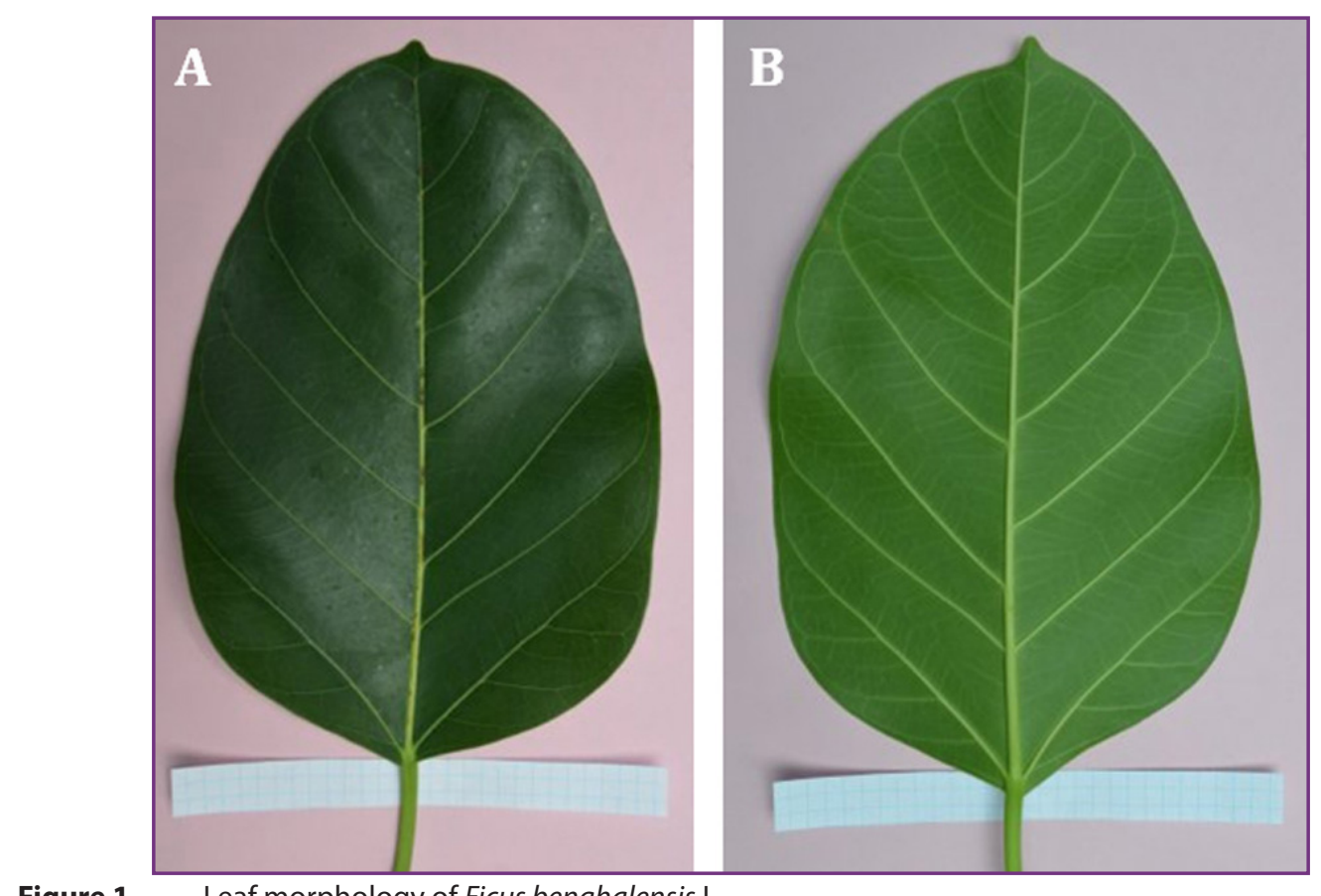

Figure 1

Leaf morphology of Ficus benghalensis L.

A - adaxial leaf surface; B - abaxial leaf surface

Antimicrobial activity assessment was performed according to the agar diffusion method described by Bauer and co-workers (1966). Gram-negative bacteria Klebsiella pneumoniae (ATCC 700603), Pseudomonas aeruginosa (ATCC 27853), and Escherichia coli (ATCC 25922), as well as Gram-positive bacteria Staphylococcus aureus (ATCC 25923), locally isolated methicillin-resistant Staphylococcus aureus and Streptococcus pneumoniae (ATCC 49619), as well as fungal strain Candida albicans were used as test organisms.

Cultures of Gram-positive and Gram-negative bacteria were suspended in sterile solution of 0.9\% normal saline and the turbidity adjusted equivalent to that of a 0.5 McFarland standard.

All the cultures were inoculated onto Mueller-Hinton ( $\mathrm{MH})$ agar plates. Sterile filter paper discs impregnated with extract were applied over each of the culture plates. Isolates of bacteria were then incubated at $37^{\circ} \mathrm{C}$ for $24 \mathrm{~h}$. The fungal organism used for the present study was Candida albicans. The plates were incubated at $27^{\circ} \mathrm{C}$. A negative control disc was impregnated with sterile ethanol used in each experiment. The antimicrobial activities of the extract tested were evaluated at the end of the inoculated period by measuring the inhibition zone diameter around each paper disc in millimeters. For each extract eight replicate trials were conducted against each organism. Zone diameters were determined and averaged. Results for the antimicrobial activities are presented as mean \pm standard error of the mean. All statistical calculation was performed on separate data from each bacterial strain.

\section{Results and discussion}

The results of antimicrobial activity screening of ethanolic extract obtained from leaves of F. benghalensis are presented in Figure 2-4. 
Ethanolic extract obtained from leaves of Ficus benghalensis showed mild antibacterial activity against Staphylococcus aureus (mean diameter of inhibition zones was $16.06 \pm 2.11 \mathrm{~mm}$ ), Escherichia coli (13.75 $\pm 0.54 \mathrm{~mm})$, and Pseudomonas aeruginosa (10.69 $\pm 1.22 \mathrm{~mm})$, while no significant antibacterial activity against Klebsiella pneumoniae and Streptococcus pneumonia, methicillinresistant Staphylococcus aureus and Candida albicans was demonstrated (Figure 2-4).

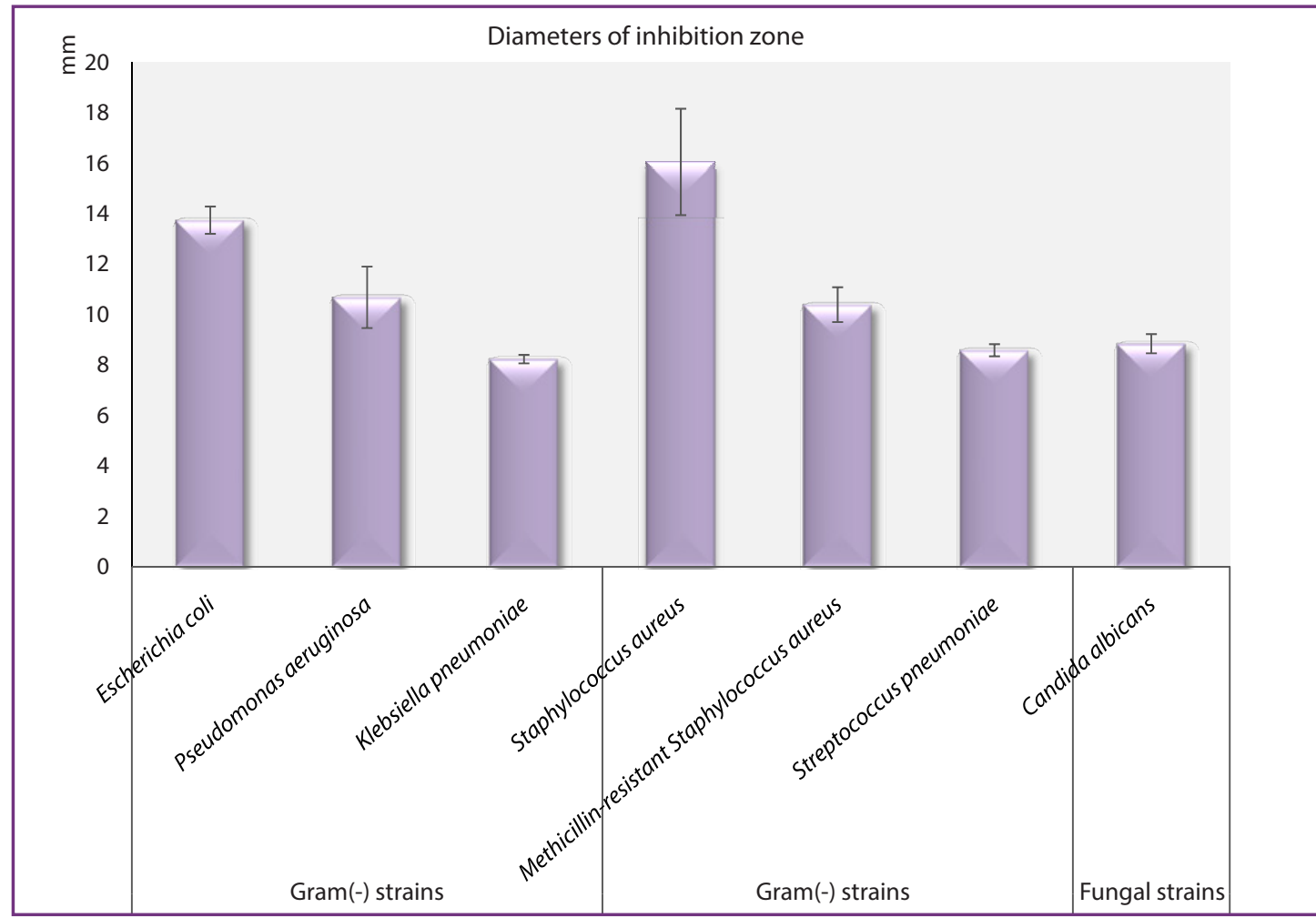

Figure 2 Antimicrobial activity of ethanolic extract obtained from Ficus benghalensis L. leaves against bacterial and fungal strains measured as diameters of inhibition zone $(M \pm m, n=8)$

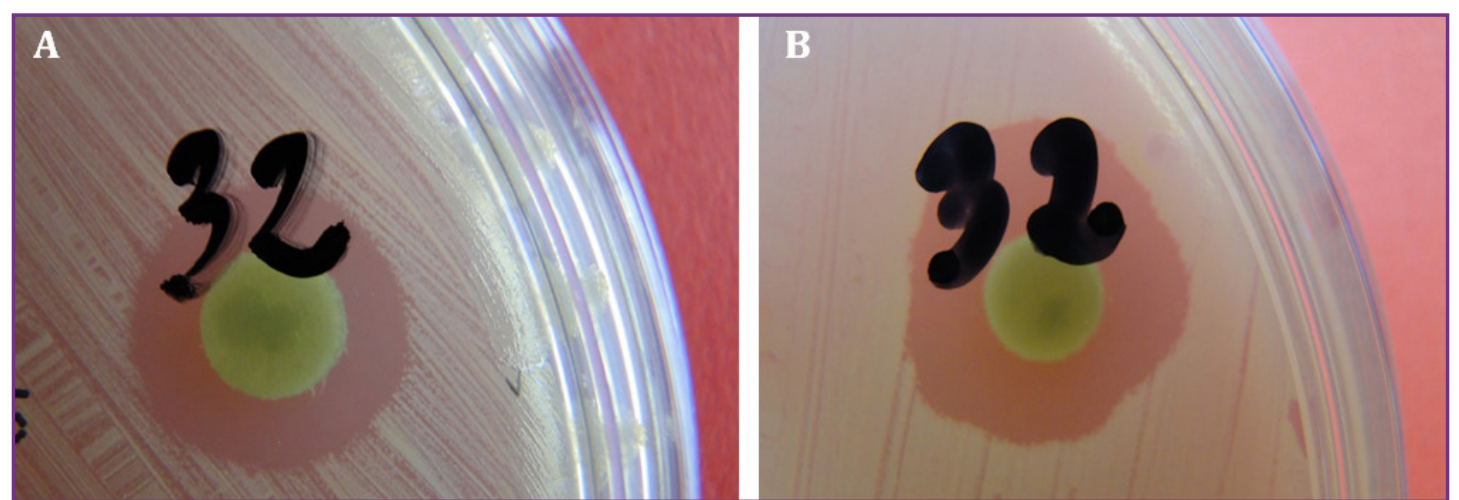

Figure 3 Antimicrobial activity of ethanolic extract obtained from Ficus benghalensis L. leaves against Gram-positive bacterial strains (A - Staphylococcus aureus; B - methicillin-resistant Staphylococcus aureus) measured as diameters of inhibition zone 


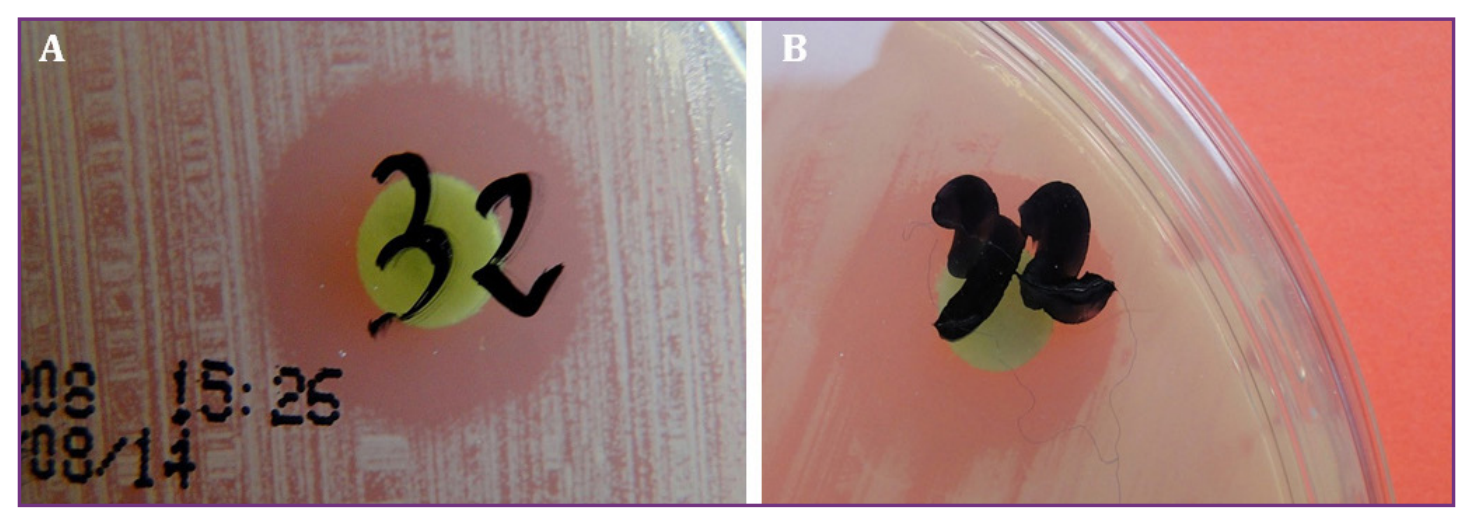

Figure 4 Antimicrobial activity of ethanolic extract obtained from Ficus benghalensis L. leaves against Gram-negative bacterial strains (A - Escherichia coli; B - Pseudomonas aeruginosa) measured as diameters of inhibition zone

Among the tested microbial strains, bacteria were found to be more sensitive to many of the test agents than fungi. The antibacterial activity was more pronounced on the Gram-positive bacteria (Staphylococcus aureus) than the Gram-negative bacteria (Escherichia and Pseudomonas aeruginosa).

The reason for the difference in sensitivity between Gram-positive and Gram-negative bacteria might be ascribed to the differences in morphological constitutions between these microorganisms, Gram-negative bacteria having an outer phospholipidic membrane carrying the structural lipopolysaccharide components (Bland et al., 2001). However, in spite of this permeability differences, some of the extracts have still exhibited some degree of inhibition against Gram-negative organisms as well (Figure 2).

Previous reports have demonstrated that the Ficus benghalensis plant possesses quite high antibacterial activity. Gayathri and Kannabiran (2009) reported high antibacterial activity of Ficus benghalensis bark aqueous extract against Staphylococcus aureus and two other bacteria species (Klebsiella pneumoniae and Pseudomonas aeruginosa), with the minimal inhibitory concentration for Staphylococcus aureus being $0,1 \mathrm{mg} / \mathrm{ml}$.

Phytochemical screening of the extracts showed that tannins and saponins significantly prevail over other chemical classes, suggesting their substantial contribution to the antimicrobial properties of the species. Singh and Watal (2010) screened aqueous and hexane extracts of different concentrations $(25,50$, and $75 \mathrm{mg} / \mathrm{ml})$ from Ficus benghalensis aerial roots against clinical isolates of Escherichia coli, Klebsiella pneumonia, and Staphylococcus aureus.

Aqueous extract showed significantly greater inhibitory activity than hexane extract. Staphylococcus aureus demonstrated the highest susceptibility among the microorganisms tested. Aqueous extract affected Staphylococcus aureus with inhibition zone diameter values of $18 \mathrm{~mm}$ (at concentration $25 \mathrm{mg} / \mathrm{ml}$ ), $22 \mathrm{~mm}$ (at $50 \mathrm{mg} / \mathrm{ml}$ ), and $24 \mathrm{~mm}$ (at $75 \mathrm{mg} / \mathrm{ml}$ ), while hexane extract showed zone diameter of 18 and $22 \mathrm{~mm}$ at concentrations 50 and $75 \mathrm{mg} / \mathrm{ml}$, respectively.

On the other hand, Valsaraj and co-workers (1997) evaluated activity of ethanolic extracts from Ficus benghalensis aerial roots and Ficus religiosa leaves, among a large number of plants, against four bacterial strains (Bacillus subtilis ATCC 6633, E. coli ATCC 11229, Pseudomonas aeruginosa ATCC 9027, and Staphylococcus aureus ATCC 6538) and two fungi (Aspergillus niger IMI 076837 
and Candida albicans IMI 349010), using the agar dilution method for the former and agar-well diffusion method for the latter. Ficus benghalensis extracts showed weak inhibition (at concentration of $25 \mathrm{mg} / \mathrm{ml}$ ) of only Bacillus subtilis and Staphylococcus aureus, while Ficus religiosa extracts were moderately active (at concentrations $6.25 \mathrm{mg} / \mathrm{ml}$ ) against Bacillus subtilis and weakly active against other bacteria.

The broad antibacterial activities of these extracts could be considered as a result of the plant secondary metabolites content. In general, Ficus species are rich sources of polyphenolic compounds. In particular, flavonoids and isoflavonoids are responsible for the extract's strong antioxidant activity that may be useful in preventing diseases involving oxidative stress (Sirisha et al., 2010; Dai et al., 2012). Ficus benghalensis has been reported to have versatile phytochemical constituents including ketones, flavonoids and flavonols, terpenoids, coumarins, esters, carbohydrates, serine protease (Ahmad et al., 2011). Leaves of Ficus benghalensis contain flavonols that are responsible for its antioxidant effects (Ahmad et al., 2011). These flavonols include quercetin-3-galactoside and rutin (Vikas and Vijay, 2010). Stem bark of Ficus benghalensis also contains bengalenosides that are glycosides or flavonoids (Vikas and Vijay, 2010). All these flavonoids consist of various sugars attached with OH groups of leucoperalgonidin, leucodelphinidin and leucocyanidin (Ahmad et al., 2011).

It is currently known that phenolic acids and flavonoids are antioxidants with high anti-inflammatory and anti-carcinogenic activities (Heijnen et al., 2001). All the detected phenolic acids are known to have antimicrobial and antioxidant properties (Jaafar et al., 2012). Some evidence suggests that the biological actions of these phenolic acids may be responsible for antimicrobial and antioxidant activities of another member of Ficus genus - Ficus benjamina (Imran et al., 2014).

Moreover, the number of studies has suggested protective effects of flavonoids against many infectious (bacterial and viral diseases) and degenerative diseases such as cardiovascular diseases, cancers, and other age-related diseases (Cook and Samman, 1996; Cushnie and Lamb, 2005; Kumar and Pandey, 2013). Flavonoids have an ability to induce human protective enzyme systems. The mechanisms involved in protection provided by flavonoids were described circumstantially in review of Kumar and Pandey (2013). Flavonoids also act as a secondary antioxidant defense system in plant tissues exposed to different abiotic and biotic stresses. Thus, their mode of antimicrobial action may be related to their ability to inactivate microbial adhesins, enzymes, cell envelope transport proteins, and so forth. Lipophilic flavonoids may also disrupt microbial membranes (Cowan, 2009; Kumar and Pandey, 2013). The aqueous or alcoholic extracts of various parts of Ficus benghalensis were found to have various pharmacological activities for example, anti-diabetic, hypocholesterolemic, hypolipidemic, anti-inflammatory, anthelmintic, antibacterial, anti-allergic and anti-tumor activity (Ahmad et al., 2011).

\section{Conclusions}

The ethanolic extract obtained from Ficus benghalensis leaves showed varying inhibitory activities against all the test organisms. Among the tested microbial strains, bacteria were found to be more sensitive to many of the test agents than fungi. The antibacterial activity was more pronounced on the Gram-positive bacteria (Staphylococcus aureus) than the Gram-negative bacteria (Escherichia and Pseudomonas aeruginosa). Ficus benghalensis has a great medicinal potential for the therapy of infections caused by Gram-positive and Gram-negative bacteria and may be used as a natural antiseptic and antimicrobial agent in medicine. Further investigation is necessary to identify those bioactive compounds, which will be a platform for clinical applications. 


\section{References}

Ahmad, S., Rao, H., Akhtar, M., Ahmad, I., Hayat, M.M., Iqbal, Z., Nisar-ur-Rahman. 2011. Phytochemical composition and pharmacological prospectus of Ficus benghalensis Linn. (Moraceae) - A review. J. Med. Plants Res., vol. 5, p. 6393-6400. DOI: 10.5897/JMPR11.455

Aswar, M., Aswar, U., Wagh, A., Watkar, B., Vyas, M., Gujar, K.M. 2008. Antimicrobial activity of Ficus benghalensis. Pharmacology on line, vol. 2, p. 715-725.

Bauer, A.W., Kirbi, W.M., Sherris, J.C., Turk, M. 1966. Antibiotic susceptibility testing by a standardized single disk method. Am. J. Clin. Pathol., vol. 45, no. 4, p. 493-496.

Berg, C.C., Corner, E.J.H. 2005. Moraceae (Ficus). Noteboom H.P. (ed.) Flora Malesiana, Ser. 1, vol. 17, Part 2. p. 1-730.

Bland, M., Vermillion, S., Soper, D., Austin, M. 2001. Antibiotic resistance patterns of group B streptococci in late third-trimester rectovaginal cultures. American Journal of Obstetrics and Gynecology, vol. 184, no. 6, p. 1125-1126. DOI: 10.1067/mob.2001.115478

Cook, N.C., Samman, S. 1996. Review:flavonoids-chemistry, metabolism, cardioprotective effects and dietary sources. Journal of Nutritional Biochemistry, vol. 7, no. 2, p. 66-76. DOI: 10.1016/S0955-2863(95)00168-9

Cowan, M.M. 1999. Plant products as antimicrobial agents. Clin. Microbiol. Rev., vol. 12, no. 4, p. 564-582.

Cushnie, T.P., Lamb, A.J. 2005. Antimicrobial activity of flavonoids. Int. J. Antimicrob. Agents, vol. 26, no. 5, p. 343-356.

Dai, J., Shen, D., Yishida, W.Y., Parrish, S.M., Williams, P.G. 2012. Isoflavonoids from Ficus benjamina and their inhibitory activity on BACE1. Planta Med., vol. 78, no. 12, p. 1357-1362. DOI: 10.1055/s-0032-1315001

Garg, V.K., Paliwal, S.K. 2011. Wound-healing activity of ethanolic and aqueous extracts of Ficus benghalensis. J. Adv. Pharm. Technol. Res., vol. 2, no. 2, p. 110-114. DOI: 10.4103/2231-4040.82957

Gayathri, M., Kannabiran, K. 2009. Antimicrobial activity of Hemidesmus indicus, Ficus benghalensis and Pterocarpus marsupium Roxb. Indian Journal of Pharmaceutical Sciences, vol. 71, no. 5, p. 578-581. DOI: 10.4103/0250-474X.58182

Heijnen, C.G., Haenen, G.R., Vanacker, F.A., Vijgh, W.J., Bast, A. 2001. Flavonoids as peroxynitrite scavengers: the role of the hydroxyl groups. Toxicol. In Vitro, vol. 15, p. 3-6. DOI: 10.1016/S0887-2333(00)00053-9

Imran, M., Rasool, N., Rizwan, K., Zubair, M., Riaz, M., Zia-ul-haq, M., Rana, U.A., Nafady, A., Jaafar, H.Z. 2014. Chemical composition and biological studies of Ficus benjamina. Chem. Cent. J., vol. 8, no. 1, p. 12. DOI: 10.1186/1752-153X-8-12.

Jaafar, H.Z., Ibrahim, M.H., Karimi, E. 2012. Phenolics and flavonoids compounds, phenylanine ammonia lyase and antioxidant activity responses to elevated $\mathrm{CO}_{2}$ in Labisia pumila (Myrsinaceae). Molecules, vol. 17, no. 6, p. 6331-6347. DOI: 10.3390/molecules17066331

Kumar, S., Pandey, A.K. 2013. Chemistry and biological activities of flavonoids: an overview. ScientificWorldJournal, vol. 2013, p. 16. DOI: 10.1155/2013/162750

Panday, D.R., Rauniar, G.P. 2016. Effect of root-extracts of Ficus benghalensis (Banyan) in memory, anxiety, muscle co-ordination and seizure in animal models. BMC Complement. Altern. Med., vol. 16, no. 1, p. 429. DOI: 10.1186/s12906-016-1413-5

Patel, M.A., Patel, P.K., Patel, M.B. 2010. Effects of ethanol extract of Ficus benghalensis (bark) on inflammatory bowel disease. Indian J. Pharmacol., vol. 42, no. 4, p. 214-218. DOI: 10.4103/0253-7613.68420.

Sharma, R.K., Chatterji, S., Rai, D.K., Mentha, S., Rai, P.K., Singh, R.K., Watal, G., Sharma, B. 2009. Antioxidant activities and phenolic contents of the aqueous extracts of some Indian medicinal plants. J. Med. Plants Res., vol. 3, p. 944-948.

Singh, R.K., Watal, G. 2010. Antimicrobial potential of Ficus benghalensis aerial roots. International Journal of Pharma and Bio Sciences, vol. 1, no. 3, p. 1-9. http://www.ijpbs.net/issue-3/12.pdf

Sirisha, N., Sreenivasulu, M., Sangeeta, K., Chetty, C.M. 2010. Antioxidant properties of Ficus species, a review. Int. J. Pharma Techn. Res., vol. 4, p. 2174-2182. 
Subramanian, P.M., Misra, G.S. 1978. Chemical constituents of Ficus benghalensis. Pol. J. Pharmacol. Pharm., vol. 30, p. 559-562.

Valdaraj, R., Pushpangadan, P., Smitt, U.W., Adsersen, A., Nyman, U. 1997. Antimicrobial screening of selected medicinal plants from India. Journal of Ethnopharmacology, vol. 58, p. 75-83.

Varanasi, S.N. 2007. A medico-historical review of Nyagrŏdha (Ficus benghalensis). Bull. Ind. Inst. Hist. Med., vol. 37, no. 2, p. 167-178.

Vikas, V.P., Vijay, R.P. 2010. Ficus benghalensis. An Overview. Int. J. Pharm. Biol. Sci., vol. 1, no. 2, p. 1-11. 